\title{
O DISPOSITIVO INTERACIONAL "PÁGINA DO CANDIDATO NO FACEBOOK" NAS ELEIÇÕES DE 2014
}

\author{
The Interactional Dispositif "Candidate's Page on Facebook" in the 2014 \\ Elections
}

\author{
El Dispositivo Interaccional "Página del Candidato en Facebook" en las \\ Elecciones de 2014
}

Lídia Raquel Herculano Maia

Professora Substituta no Curso de Relações Públicas da UFPB

lidiarhmaia@outlook.com

\section{Resumo}

Essa pesquisa tem como objetivo analisar as páginas do Facebook dos três principais presidenciáveis, nas eleições brasileiras de 2014, enquanto dispositivos interacionais nos quais se organizaram sistemas de relações entre candidatos e eleitores. Para alcançar tal objetivo, foi realizada uma pesquisa exploratória, de abordagem qualitativa, utilizando a perspectiva etnometodológica. A problemática central se constitui na articulação entre o contexto da campanha presidencial, as lógicas do Facebook e as estratégias realizadas pelos participantes das páginas observadas. Concluindo-se que, em cada um dos três dispositivos, as funções do meio foram diferentemente acionadas pelos participantes (candidatos e suas equipes e eleitores) no que tange ao objetivo comunicacional, de fazer a interação acontecer, e político, de vencer as eleições.

Palavras-chave: Dispositivos Interacionais. Campanha Presidencial. Facebook.

\begin{abstract}
This research aims to analyze the Facebook pages of the three main presidential candidates in the 2014 Brazilian election as interactional dispositifs in which relationship systems were organized between candidates and voters. To achieve this objective, exploratory research with a qualitative approach was carried out, using the ethnomethodological perspective. The research problem is built in the articulation among the context of the presidential campaign, the logic of Facebook and the strategies carried out by the participants of the observed pages. We conclude that, in each one of the three dispositifs, the functions of the media were triggered in different ways by the participants (candidates and their teams, and voters) regarding the communicational goal, of making the interaction happens, and the political goal, of winning the elections.
\end{abstract}

\footnotetext{
${ }^{1}$ Pesquisa financiada pela Capes (Coordenação de Aperfeiçoamento de Pessoal de Nível Superior - Código de Financiamento 001). Uma primeira versão deste texto foi apresentada no II Seminário Internacional de Pesquisas em Midiatização e Processos Sociais, São Leopoldo-RS, 2018.
} 
Key words: Interactional Dispositif. Presidential Campaign. Facebook.

\section{Resumen}

Esta investigación tiene como objetivo analizar las páginas de Facebook de los tres principales candidatos a presidente en las elecciones brasileñas de 2014 como dispositivos interaccionales en los cuales se organizan sistemas de relaciones entre candidatos y electores. Para lograr este objetivo, se realizó una investigación exploratoria con enfoque cualitativo, desde la perspectiva etnometodológica. La problemática central se constituye en la articulación entre el contexto de la campaña presidencial, las lógicas de Facebook y las estrategias realizadas por los participantes de las páginas observadas. Concluimos que, en cada uno de los tres dispositivos, las funciones del medio fueran accionadas en forma diferente por los participantes (candidatos y sus equipos, y electores) en lo que concierne al objetivo comunicacional, de hacer que la interacción acontezca, y político, de vencer las elecciones.

Palabras clave: Dispositivos Interaccionales. Campaña Presidencial. Facebook.

\section{INTRODUÇÃO}

O presente artigo investiga os processos interacionais desenvolvidos pelos participantes das páginas do Facebook dos três principais presidenciáveis nas eleições de 2014 - Dilma Rousseff (PT), Aécio Neves (PSDB) e Marina Silva (que naquele momento integrava o PSB). Essa eleição resultou na votação mais acirrada da história do país, com um segundo turno definido por uma margem de 3,26 pontos percentuais. E apresentou intensos desdobramentos: o segundo colocado (Aécio Neves) não aceitou o resultado do pleito e pediu auditoria das urnas, seu partido (PSDB) pediu a cassação da chapa vitoriosa (o que não aconteceu) e opositores apresentaram dezenas de pedidos de impeachment contra a candidata eleita (Dilma Rousseff) - até que um deles foi aceito em 2015 e concluído em agosto de 2016.

A eleição presidencial seguinte (2018) mostrou a exasperação dessa polarização, já que a direita, após perder 4 eleições apostando no PSDB, resolveu migrar seus votos para o candidato de extrema-direita, Jair Bolsonaro (que naquele momento integrava o PSL). Todos esses desdobramentos, mostram a relevância do estudo das eleições presidenciais de 2014, que ficaram marcadas também pelos índices de conectividade e discussão política. Segundo dados da BBC Brasil, a disputa eleitoral daquele ano movimentou 674,4 milhões de interações no Facebook, conferindo a esse pleito o status de "eleição mais conectada do mundo" (BARIFOUSE, 2014).

Assim, o cenário das eleições presidenciais de 2014 nos impeliu à observação do que chamamos de dispositivo interacional "página do candidato" no Facebook. Baseando-se na percepção foucaultiana de dispositivo enquanto "sistema de relações", Braga (2017) propõe o 
conceito de "dispositivos interacionais" para se referir às matrizes, culturalmente disponíveis no ambiente social, e aos modos práticos compartilhados para fazer avançar a interação considerando-se ainda os meios utilizados e o âmbito no qual ela se desenvolve. Entendemos que nas eleições de 2014, tais dispositivos foram tentativamente formados nas páginas do Facebook de Dilma Rousseff, Aécio Neves e Marina Silva, a partir das interações desenvolvidas pelos eleitores e equipes de campanha.

Destarte, a problemática da pesquisa delineia-se na articulação do contexto mais amplo da campanha presidencial somado aos usos e apropriações do Facebook para reforço dos vínculos interacionais entre candidatos e eleitores. $\mathrm{O}$ objetivo principal do estudo é analisar as páginas do Facebook de cada candidato como um dispositivo interacional, no qual se organizam lógicas e se agenciam as funcionalidades dessa mídia social com o intuito de promover as campanhas presidenciais em questão.

Propõe-se, então, a estruturação da discussão do caso em três itens que contemplam: a) as lógicas do processo (campanha presidencial); b); as lógicas do meio sociotécnico (Facebook) e principalmente c) as lógicas produzidas na singularidade da própria interação (no dispositivo "página do candidato").

\section{NOTAS SOBRE O MÉTODO}

Para alcançar o objetivo proposto, recorremos a uma pesquisa exploratória aliada à perspectiva etnometodológica (WATSON E GASTALDO, 2015) - para que se possa entender o sistema de relações desenvolvido durante a campanha de 2014 em páginas do Facebook. Ao longo de 2015 escrutinamos as páginas oficiais do Facebook dos três principais presidenciáveis do pleito de 2014, buscando indícios que, articulados, pudessem auxiliar na formulação deste caso de pesquisa. Os dados empíricos coletados para a pesquisa compreendem o período de 20 de agosto a 26 de outubro de 2014 - respectivamente, data de entrada de Marina Silva na disputa e votação do segundo turno que marcou o término da eleição.

Tendo em vista que esse período foi marcado por intensa circulação de conteúdos nas páginas observadas, julgamos pertinente elencar as principais postagens ( 29 da página de Aécio Neves e Dilma Rousseff, cada, e 20 de Marina Silva ${ }^{2}$ ) e seus respectivos comentários,

\footnotetext{
${ }^{2}$ Essa amostra foi coletada a propósito de nossa pesquisa de tese (MAIA, 2019). Sendo este paper, portanto, resultado de um recorte dessa pesquisa de doutoramento. Devido às limitações de caracteres deste artigo, trabalharemos com apenas alguns exemplos de posts e comentários. Não obstante, as inferências aqui realizadas são provenientes da análise desses 78 posts e dos 3.900 comentários extraídos deles.
} 
representativos dos momentos que, ao nosso ver, se constituem como os mais relevantes das campanhas desses presidenciáveis. Tal relevância fora mensurada, principalmente, com base na intensidade de interações que geravam e na diversidade de estratégias que apresentavam. Já os comentários, diante da infinidade com que se apresentavam, foram restritos aos cinquenta primeiros (comentários e suas respectivas respostas ${ }^{3}$ ), organizados por relevância ${ }^{4}$.

\section{DISPOSITIVOS INTERACIONAIS}

Discutimos aqui o conceito de "dispositivos interacionais" (BRAGA, 2011; 2017) por entender as páginas dos candidatos enquanto espaços nos quais se organizam episódios interacionais, agenciados a partir das postagens dos candidatos e modelados no processo conversacional desenvolvido no âmbito dos comentários. Braga (2011, p.6) explica que em cada processo social, "a sociedade gera [...] determinados padrões para seu funcionamento. Tais práticas acabam se organizando em dispositivos variados, que de algum modo 'modelam' o funcionamento comunicacional que aí ocorre". Assim, a partir de processos tentativos e do desenvolvimento de modos práticos compartilhados para fazer avançar a interação, em episódios comunicacionais de uma mesma ordem, a sociedade acaba organizando o que o autor chama de "dispositivos interacionais".

Esse conceito demonstra-se profícuo para o estudo de casos comunicacionais porque nos auxilia a esquadrinhar as especificidades de cada objeto a partir de perguntas que podem revelar as lógicas comuns presentes em fenômenos diversos estudados por pesquisadores da comunicação. Sendo assim, não se trata de simplesmente aplicar o conceito de forma categorizante para explicar o objeto segundo as premissas da teoria estudada. Mas sim de lançar ao objeto perguntas com potencial de destacar suas lógicas, de modo que seja possível propor uma modelização do caso. Com essa proposta, Braga (2017) nos apresenta um conjunto de premissas e perguntas abrangentes a partir das quais podem se desenvolver questões mais diretamente voltadas ao objeto em observação. Um exemplo de premissa

\footnotetext{
${ }^{3}$ Assim, para cada postagem temos uma faixa de oito a dez comentários principais e suas respectivas respostas. Resultando, sempre, numa amostra de 50 comentários por postagem.

${ }^{4}$ Os comentários escritos em postagens de páginas no Facebook podem ser exibidos aos usuários em ordem de relevância (aferida com base em quantas "curtidas" e respostas o comentário recebeu) ou de data de publicação. Consideramos que a coleta por ordem de relevância demonstra-se pertinente porque quando alguém "curte" um comentário é como se estivesse dizendo: "eu compartilho deste pensamento, concordo com você". As respostas, por sua vez, mostram que tal comentário acionou reações nos demais internautas, apresentando, assim, potencial para o desenvolvimento de conversações políticas. Portanto, essa faixa de comentários colhidos demonstra-se suficiente para a análise porque foram reverberados, atestados pelos grupos observados nessa pesquisa.
} 
heurística esboçada pelo autor é: "se a comunicação é tentativa, o que - aqui, nesse caso em estudo - está sendo tentado?” (BRAGA, 2017, p.50). Orientados por essa questão, debruçamo-nos na observação e descrição das ações político/interacionais tentativamente empreendidas pelos participantes das páginas estudadas.

No caso do dispositivo "página do candidato", observamos que os participantes (eleitores e candidatos) se organizam com o objetivo social final de fazer o seu candidato vencer as eleições ao mesmo tempo em que, através das postagens e comentários, gerenciavam objetivos individuais pontuais de tentativamente melhorar a imagem dos candidatos, detratar os concorrentes, sanar dúvidas, prestar apoio mútuo aos pares, etc. Essas tentativas, junto a outros fatores, organizaram o dispositivo "página do candidato". Esse dispositivo - organizado a partir das práticas dos usuários, do contexto (no caso eleitoral) em que tais práticas se inserem e da estrutura do meio técnico (Facebook) - modela o funcionamento comunicacional das interações que, por sua vez, geraram o dispositivo.

Mas, essas matrizes interacionais, geradas no processo, não são fixas, simplesmente aplicáveis pelos participantes da interação. Ao invés disso, no processo comunicacional, “em interação com uma diversidade de códigos [...], os participantes acionam também processos inferenciais ad-hoc [...] que por sua vez podem incidir sobre os próprios códigos e sistemas" (BRAGA, 2011, p.6). Desse modo, acionamos tal conceito por entender que o dispositivo "página do candidato" é marcado também por forte experimentação social, não se restringindo unicamente aos postulados de uso e às regras estabelecidas pelo Facebook. São vários os componentes que delineiam o sistema de relações e viabilizam as interações entre os participantes (eleitores e marqueteiros) das páginas observadas. Sendo assim, esse conceito demonstra-se pertinente para que possamos entender e fazer perguntas sobre as lógicas interacionais tentativamente acionadas pelos participantes das páginas dos candidatos no processo de fazer marketing político, no contexto das eleições de 2014.

\section{A FORMAÇÃO DO DISPOSITIVO "PÁGINA DO CANDIDATO"}

\subsection{Breve contextualização da campanha de 2014}

Uma combinação de fatores caracterizou o cenário político das eleições presidenciais de 2014: 1) a campanha de reeleição de Dilma Rousseff tinha como trunfo o sucesso dos programas sociais, "responsáveis pela ascensão social de muitos brasileiros, [mas] o contexto econômico sinalizava baixo crescimento e no plano político, escândalos de corrupção envolviam figuras do PT" (ROSSINI et al., 2016, p.151); 2) assim, havia o desgaste do 
Partido dos Trabalhadores perante as denúncias de corrupção após 12 anos de governo federal; 3) some-se a isto os protestos de junho de 2013 - quando, após o anúncio do aumento na tarifa de transporte público, milhões de pessoas foram às ruas de diversas cidades brasileiras para reivindicar, inicialmente, o Passe Livre para os estudantes da rede pública de ensino, no que parecia ser uma mobilização de grupos à esquerda do governo que depois foi apropriada por grupos de direita, os quais aderiram às manifestações dizendo lutar "contra tudo".

"Além disso, animados com as manifestações fora do controle do governo (...), os partidos da oposição liberal conservadora passaram a ter um maior ativismo oposicionista, rompendo com certa passividade que predominou nos governos petistas" (ALMEIDA, 2015, p.13). Assim, o caráter difuso dessas manifestações contribuiu também para "a expansão da cultura dos protestos e da apropriação do espaço público por vários setores sociais, incluída a direita" (PENTEADO et al., 2016, p.276) - tendo como consequência o avanço de uma Rede Antipetista aproximadamente um ano antes do período eleitoral de 2014 (SANTOS JÚNIOR, 2016). Diante disso, muitas "direitas" começaram a se articular a partir de 2014 - todas, no entanto, com uma causa única: combater o PT e a candidatura de Dilma. Ainda assim, uma Pesquisa Ibope de 7 de agosto de 2014 apresentava Dilma Rousseff com larga vantagem na disputa, com $38 \%$ das intenções de voto, enquanto Aécio encontrava-se confortavelmente na segunda posição com 23\%, seguido por Eduardo Campos, com 9\% (UOL, 2014). Dessa forma, desde o começo da eleição em 06 de julho, tudo levava a crer que a disputa seria marcada pela polarização que vem caracterizando as eleições presidenciais brasileiras desde 1994: PT versus PSDB.

A então presidenta Dilma Rousseff (PT) buscava a sua reeleição; Aécio Neves (PSDB), ex-governador do estado de Minas Gerais, pleiteava o retorno de seu partido ao governo federal, que esteve na presidência entre 1995 e 2002, com o governo de Fernando Henrique Cardoso; e Eduardo Campos, ex-governador de Pernambuco, representava o PSB, tendo como vice Marina Silva, que naquele momento tentava construir seu próprio partido (Rede Sustentabilidade). Até que em 13 de agosto de 2014, Campos faleceu em acidente aéreo e, num cenário de grande comoção nacional, sua vice foi escolhida pelo PSB para a disputa do cargo. Marina Silva já gozava de certo capital político, tendo em vista seu trabalho como ex-ministra do Meio Ambiente e sua candidatura à presidência nas eleições de 2010. Assim, sua entrada na disputa provocou, então, um acirramento progressivo do conflito eleitoral. 
Todo esse contexto apresentado até aqui, resultou na apertada reeleição de Dilma Rousseff com 51,64\% dos votos válidos, contra 48,36\% do candidato Aécio Neves. Destarte, na eleição presidencial mais acirrada da história do país, não apenas os candidatos se empenharam em conquistar votos até o último momento, bem como seu eleitorado também o fez. Uma das formas que encontraram para isso foi através da ocupação de sites de redes sociais (principalmente o Facebook) para o debate político.

\subsection{Facebook}

Sites de redes sociais podem ser definidos como um serviço online que permite aos usuários a criação de perfis públicos ou privados e a navegação em outros perfis de usuários (HARLOW, 2013). Nessas mídias sociais, os internautas podem, dentre outras coisas, publicar conteúdo, criar laços entre si e compartilhar opiniões, notícias e afetos. As últimas eleições brasileiras - e outras realizadas em diferentes partes do mundo (SORENSEN, 2016) - nos mostraram que o Facebook, por exemplo, pode ser utilizado também como um espaço para discussões políticas, tanto nas páginas de usuários comuns como nas dos políticos.

Não obstante, o Facebook vem sendo alvo de inúmeras críticas em função de sua utilização em campanhas e movimentos políticos ao redor do mundo. Os problemas apontados vão desde o uso de robôs eletrônicos para produção de conteúdo político (RUEDIGER, 2017) até a questão das notícias falsas, que agora se propagam numa velocidade alarmante já que o conteúdo pode circular entre usuários sem constrangimentos de verificação de fatos, filtragem significativa de terceiros ou julgamento editorial (ALLCOTT \& GENTZKOW, 2017).

Há ainda críticas aos algoritmos utilizados pelo Facebook, que tendem a atuar no sentido de apresentar aos usuários informações que reforcem seu ponto de vista. Essas configurações algorítmicas modelam a experiência de uso do Facebook, com base nos rastros de navegação do usuário. O site de rede social criado por Mark Zuckerberg em 2004 armazena todas as informações e atividades de seus usuários realizadas dentro ou até mesmo fora da plataforma ${ }^{5}$, supostamente com o intuito de oferecer serviços personalizados a cada internauta.

\footnotetext{
${ }^{5}$ Para coletar dados das atividades dos usuários fora do site, o Facebook usa a ferramenta "Facebook Connect", que permite ao internauta interagir com outros sites a partir do login no Facebook. Assim, a pessoa pode usar os serviços de outro site através do seu login e senha do Facebook. A problemática dessa suposta facilidade é que ao usar sua conta do Facebook para se conectar a outro site, o internauta acaba cedendo à rede social o registro das ações realizadas fora da plataforma e dentro do site parceiro. E o site parceiro, por sua vez, também recebe o registro das atividades do internauta no Facebook.
} 
Ao criar uma experiência personalizada para cada usuário, com base no registro de suas atividades, os algoritmos utilizados pelo Facebook tendem a atuar no sentido de criar "bolhas ideológicas" ou aquilo que Eli Pariser (2011) denominou de "filtro bolha". Esse filtro bolha produzido por sites de busca e redes sociais, na visão de Pariser (2011), atua como uma espécie de lente de câmera, mediando e restringindo o contato do usuário com as fontes de informações disponíveis online. Em nível pessoal, corre-se o risco do reforço de preconceitos, estereótipos e ideias equivocadas sobre pessoas e grupos sociais. Em termos sociais, os custos desse filtro também são altos, já que preso numa bolha de conteúdos que apenas reforçam um mesmo ponto de vista, o cidadão tem menor possibilidade de perceber argumentos e demandas diferentes como sendo válidos e dignos de atenção (PARISER, 2011) - o que sem dúvida demonstra-se danoso para a democracia.

Não obstante, ainda que os usuários do Facebook vejam em suas timelines apenas conteúdos com os quais já interagiram, existe a possibilidade de acessar outras páginas e perfis no site. A partir das observações empíricas realizadas, temos visto que algumas pessoas “curtem" e/ou comentam em páginas mesmo sem concordar com o conteúdo nelas postado. Foi possível constatar, por exemplo, muitas mensagens contrárias a Dilma na sessão de comentários de sua página, o que indica a presença de eleitores que discordavam de sua candidatura. É importante reconhecer, todavia, que, por estar envolto em bolhas ideológicas que muitas vezes apresentam o outro de forma distorcida, esse olhar para o diferente, não raro, demonstra-se viciado, carregado de ideias preconcebidas. Assim é que, nas discussões evidenciadas nas páginas estudadas nesta pesquisa, muitas vezes imperam o preconceito, a incivilidade e uma notável falta de disposição em atentar para o argumento do outro. No próximo tópico discutiremos como essa falta de propensão para o diálogo acaba interferindo no curso dos debates estabelecidos nas páginas estudadas.

\subsection{O dispositivo "página do candidato"}

Até um dia antes da realização do primeiro turno eleitoral, ocorrido em 05 de outubro de 2014, a página de Dilma contava com 1,2 milhão de curtidas, enquanto Marina possuía quase o dobro (2,2 milhões) e Aécio detinha 1,8 milhão e de likes (CAPELAS, 2014). Em cada uma dessas páginas públicas, as equipes de campanha forneciam conteúdo que ia desde informações sobre propostas e agenda de campanha do candidato até ataques aos oponentes, sendo este último um dos principais recursos utilizados no período estudado. Esse conteúdo 
era transmitido em postagens nas quais se mesclavam textos, fotos, ilustrações, vídeos, links para outros sites do candidato ou de conteúdo jornalístico etc.

Marina e Aécio aproveitaram as possibilidades do meio para sanar dúvidas ou falar diretamente com eleitores em particular, de forma que a reposta pudesse alcançar a todos no plural. Esse uso do meio para sanar dúvidas dos eleitores foi especialmente importante no caso de Marina Silva, tendo em vista que suas propostas foram duramente criticadas pelos oponentes e, além disso, seu programa de governo ainda sofreu alterações durante a campanha (que segundo ela teriam se dado em função de um erro estrutural na produção do documento, enquanto segundo seus detratores se tratava de uma reação às ameaças feitas pelo pastor Silas Malafaia em relação aos pontos que atendiam às demandas do público $\mathrm{LGBT}^{6}$ ). Ao se deparar com várias perguntas de eleitores no espaço destinado aos comentários, a equipe de campanha não apenas produzia comentários-resposta como também criava posts abordando assuntos que pareciam não estar totalmente claros para os eleitores.

Dilma Rousseff, por sua vez, raramente respondia aos comentários de internautas e quando o fazia usava apenas uma imagem protocolar, agradecendo o apoio recebido. Por outro lado, essa candidata foi a única que usou o recurso "compartilhar" do Facebook para publicar em sua página conteúdos produzidos por amadores. Essa estratégia parece ter sido gerada a partir da observação das atividades dos eleitores na página da candidata e em seus perfis pessoais - já que uma narrativa comumente utilizada por eles era aquela que buscava um entrelaçamento entre os programas sociais implementados nos 12 anos de gestão presidencial petista e os acontecimentos que marcaram suas vidas. Assim, eram comuns comentários na página da candidata onde alguns eleitores diziam como os governos petistas tinham lhes auxiliado a comprar casa própria ou ter acesso à universidade, por exemplo. Diante disso, a equipe convidou os eleitores a postarem conteúdo favorável à candidata usando a hashtag \#FacedaDilma, para que, assim, tais publicações pudessem ser localizadas e compartilhadas na página da presidenciável. Como aconteceu com a publicação deste eleitor que fez uma selfie mostrando seu diploma e narrando como a história de sua vida e de sua família foram perpassadas pelos programas sociais desenvolvidos por Lula e Dilma (PT):

\footnotetext{
${ }^{6}$ Maiores informações sobre o caso podem ser consultadas em: "Campanha de Marina tira do programa apoio a casamento gay". G1, 30 ago. 2014. Disponível em:

<http://g1.globo.com/politica/eleicoes/2014/noticia/2014/08/campanha-de-marina-tira-do-programa-trechosobre-casamento-gay.html>. Acesso em: 05 out. 2017.
} 
Figura 1 - \#FaceDaDilma

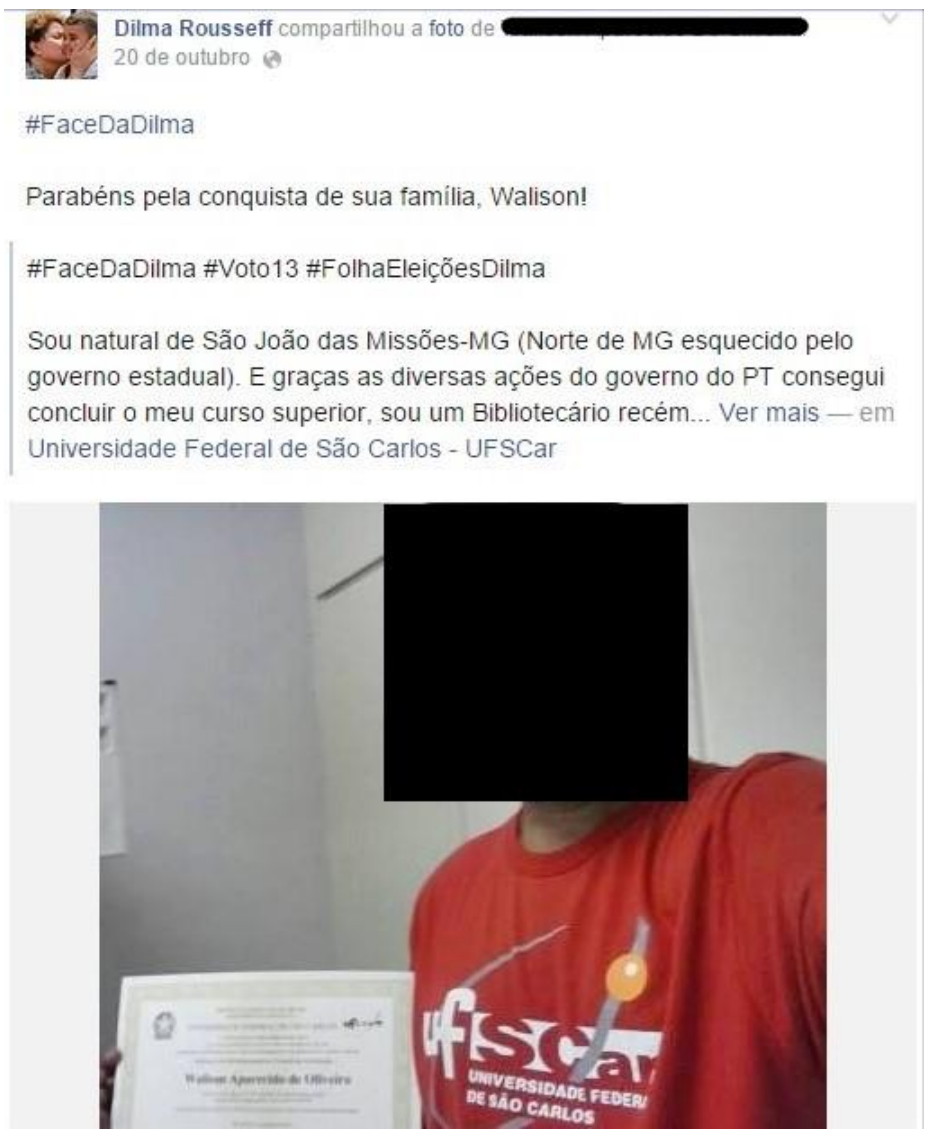

Fonte: Página oficial de Dilma Rouseff no Facebook (Online).

O uso dos testemunhais, nesses moldes da Figura 1, demonstra uma inovação, tendo em vista que uma das lógicas que parecem implícitas no uso do Facebook é que as pessoas que possuem destacada visibilidade não compartilham produções de sujeitos que não detêm capital social naquela rede. Mas, nesse caso, através do recurso da hashtag, a campanha de Dilma decidiu "inverter" um pouco essa lógica estabelecida, compartilhando publicações produzidas por eleitores.

Na tentativa de se aproximar dos eleitores, os candidatos também faziam uso de hashtags, emoticons, linguagem coloquial e estética do meio técnico. Dilma Rousseff, por exemplo, sempre utilizava emoticons acompanhados de frases para expressar como ela estava se sentindo diante dos acontecimentos da campanha, o que parecia ser uma tentativa de humanizar a figura da candidata. Após sofrer um mal-estar durante o debate do SBT, por exemplo, a candidata diz que está "se sentido determinada", como se pode ver na Figura 2. 
Figura 2 - Dilma "se sentindo determinada"

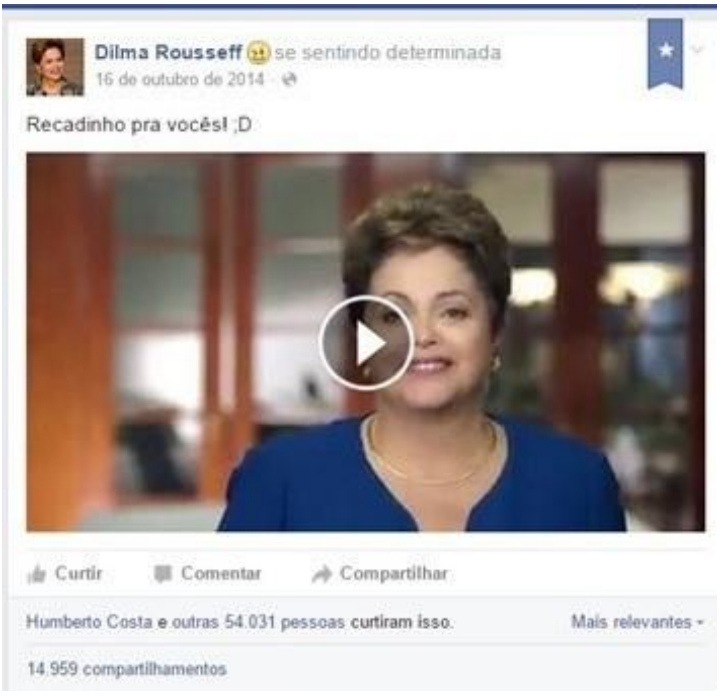

Fonte: Página oficial de Dilma Rouseff no Facebook (Online).

Essa estratégia da política coloquial era ainda mais explorada pelo candidato Aécio Neves, que produzia alguns vídeos em baixa resolução, num ambiente que aparentava ser sua casa, como se pode observar na Figura 3. A baixa resolução foi adotada, principalmente, para facilitar o compartilhamento do material no aplicativo de troca de mensagens mais popular do Brasil, o WhatsApp. Já a escolha por um ambiente informal, como sua casa, parece se dar com o intuito de trazer o internauta para a intimidade de seu lar e forjar um certo amadorismo, tal qual ocorre com os materiais audiovisuais produzidos pelos usuários comuns das redes sociais virtuais. A equipe de campanha digital de Dilma também transmitiu vídeos pelo WhatsApp, mas com a mesma qualidade técnica dos vídeos veiculados na $\mathrm{TV}^{7}$. Na verdade, no caso dessa candidata, trata-se de materiais pensados para circular em diversas mídias, sem tanta preocupação em adequar-se às lógicas dos meios.

Nessa postagem, Aécio Neves performatiza uma indignação com relação às denúncias de corrupção envolvendo a Petrobras e o Partido dos Trabalhadores. Tal vídeo, filmado a partir de um telefone celular, fora postado logo pela manhã e nele o candidato aparece com expressão de assombro, defendendo que o país acordou "perplexo com as mais graves denúncias de corrupção da nossa história”. O candidato tenta, assim, demonstrar sinergia entre suas falas e ações e as de seus eleitores, sua estratégia é a de "ser um" com eles. Isso é demonstrado, inclusive, no uso da primeira

\footnotetext{
${ }^{7}$ Para saber mais sobre o uso do WhatsApp na campanha eleitoral de 2014, recomendamos a leitura da seguinte matéria do Jornal Folha de São Paulo: <https://www1.folha.uol.com.br/poder/2014/10/1535556-usado-de-formaostensiva-whatsapp-vira-campo-de-batalha-na-campanha.shtml>. Acesso em: 20 ago. 2018.
} 
pessoa do plural, nos comentários produzidos pela equipe de campanha na página do Facebook. Em reposta ao apoio demonstrado por uma eleitora, a equipe de Aécio diz: "vamos mudar o Brasil, porque escolhemos Aécio para governar o Brasil. \#EquipeAécio45”.

Figura 3 - Vídeo amador na página do candidato Aécio Neves

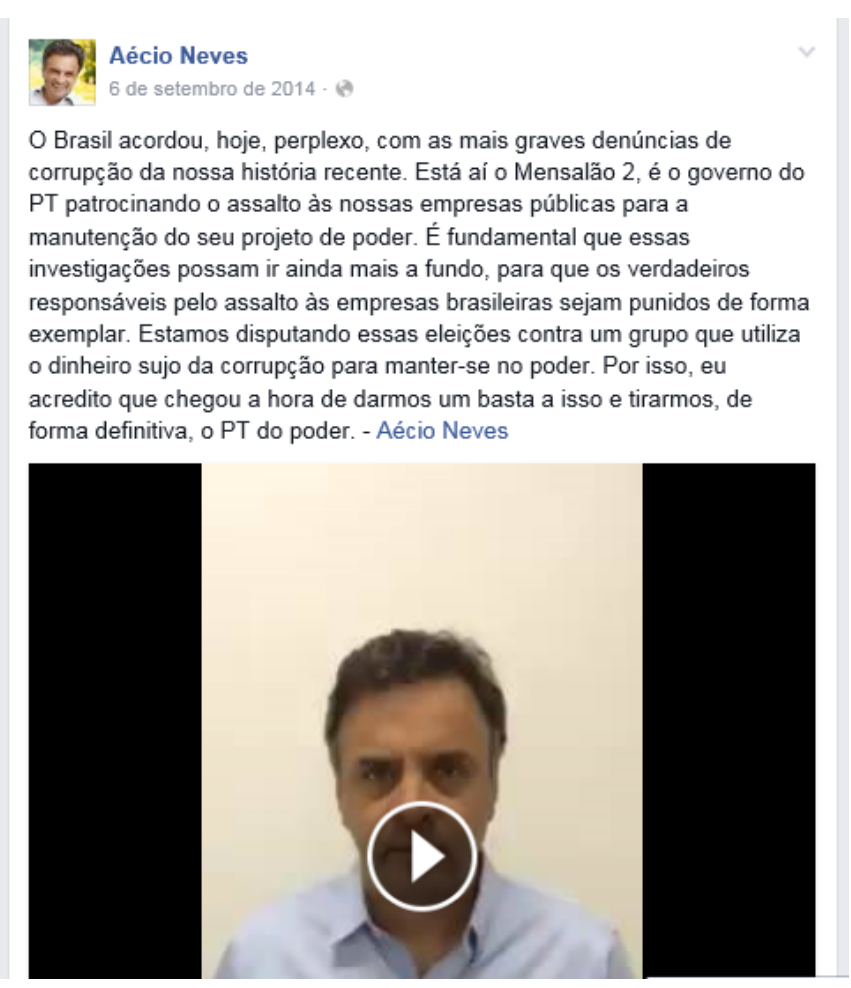

Fonte: Página oficial de Aécio Neves no Facebook (Online).

Os eleitores, por sua vez, também tentavam se sentir parte das campanhas que apoiavam e se esforçavam no sentido de prestar uma espécie de assessoria à candidatura com a qual se identificavam. Sempre que o político participava de um debate televisionado, por exemplo, os comentadores realizavam uma espécie de leitura dos acontecimentos para sugerir que tipo de comportamento o candidato deveria adotar, que assuntos e com que abordagens. Como se pode observar na Figura 4, que apresenta um exemplo extraído da página de Marina Silva: 
Figura 4 - Análise dos eleitores de Marina com relação à postura da candidata.

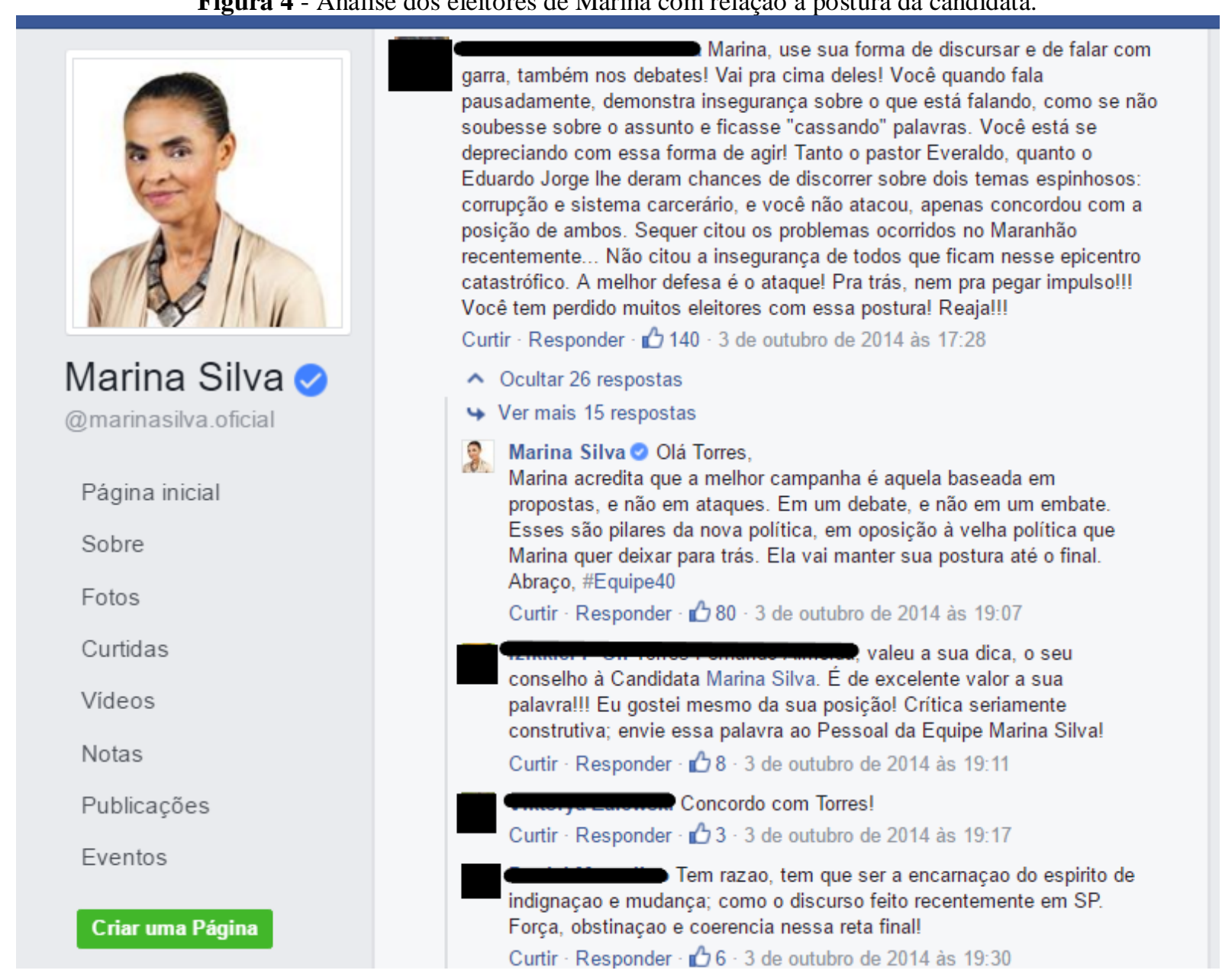

Fonte: Página oficial de Marina Silva no Facebook (Online).

Como se pode perceber, esses eleitores sugerem que a candidata deveria mudar sua postura, que seria passiva e insegura na opinião deles. Fica nítido aí o imaginário do eleitorado em relação ao debate político como uma espécie de ringue, no qual os candidatos devem, sobretudo, atacar os oponentes: "vai pra cima deles", "você não atacou”, "apenas concordou", "defesa é (..) ataque", "Reaja". Ao que a equipe respondia com a defesa irredutível da forma de fazer política pretendida pela candidata: "baseada em propostas, e não em ataques. Em um debate, e não em um embate". Os demais comentadores, que "entram" na conversa, seguem adotando a postura de "consultores políticos", analisando o comportamento da candidata e sugerindo como deve prosseguir a campanha.

Por outro lado, os eleitores desses três candidatos não mediam esforços para defender o presidenciável escolhido de ataques advindos de eleitores que escolheram candidatos opostos. Já que era comum o movimento de eleitores de candidatos adversários na página de candidatos preteridos 
apenas para criticar sua personalidade, seus planos de governo ou seus eleitores. Tal atitude era rechaçada pelos eleitores que aderiram à campanha do candidato dono da página da qual eles sentiam-se parte. Fazer do divergente um inimigo a ser combatido era uma das principais estratégias utilizadas por muitos comentaristas no sentido de se esquivar da necessidade de expor argumentos para o desenvolvimento do debate. Se o "outro" é "nosso" inimigo, deve ser rechaçado. Não importa o que ele tenha a dizer.

Além do ataque pessoal ou argumentum ad personam - que segundo Schopenhauer (2014) seria o último recurso empregado num debate, quando não se tem argumentos para combater o oponente -, outra estratégia bastante utilizada pelos eleitores dos três candidatos era criticar o candidato ou grupo de eleitores oponentes quando o presidenciável escolhido por eles recebia alguma acusação. Como no exemplo a seguir:

Comentarista 1 No dia 26 vamos nos vestir de vermelho e votar Campanha VOU DE VERMELHO VOTAR \#voudevermelhovotar

Comentarista 2 VOCÊS SÃO A VERGONHA DESTA NAÇÃO !!! EMPREITEIRAS REPASSARAM DINHEIRO DESVIADO DA PETROBRAS PARA A CAMPANHA PRESIDENCIAL DA DILMA E DO PT EM 2010. (...).

Fonte: Revista Veja, edição 2396, páginas 70 a 75.

Comentarista 3 Comentarista 2, E A Pasta rosa do PSDB ? a divida externa impagavel que ia e ia dinheiro e nunka pagava? O Dinheiro na Cuéca? O Avião cheio de drogas? Se for pra falar n fale apenas de um! Se o PT fez Petrolão o Psdb fez Petrola\$\$\$\$\$ $\$$ OME.

Comentarista 4 Acorda Comentarista 2, Veja e Globo é que é uma vergonha nacional, porque a Media não quer o bem do povo, PSDB SEMPRE foram corruptos até a raiz e mídia nunca mostrou nada! Você deve pelo menos se perguntar por que será? (...)

(Comentários em postagem na qual a página oficial de Dilma Rousseff compartilha o relato de história de vida de um eleitor, conforme mostrado na Figura 1 deste artigo).

A postagem inicial, produzida por um eleitor e compartilhada pela equipe de campanha, dizia respeito às conquistas que ele obteve graças aos programas sociais implementados na gestão presidencial do PT. Ao que o comentarista que aparece no topo dos comentários exibidos, devido ao número de curtidas que seu comentário recebeu (1.067), responde com o conclame a ir votar usando trajes vermelhos. Outro eleitor, que certamente não optou pela candidata, "entra" na conversa para desqualificar o grupo que ali se encontra: "vocês são a vergonha desta nação" e a partir daí desenvolve seu argumento, que gira em 
torno de denúncias feitas ao PT, e por último cita a fonte utilizada para a construção do mesmo. O eleitor seguinte passa a apontar as acusações que pesam contra o PSDB. A estratégia nesse caso é a seguinte: se ele falou mal de X por quem eu me posiciono a favor, eu falo mal de $\mathrm{Y}$ a quem ele provavelmente escolheu. A próxima eleitora que entra no debate passa a atacar as fontes utilizadas pelo internauta contrário à Dilma. Nesses dois últimos casos percebe-se que nenhum dos dois eleitores atacaram os argumentos do comentário oponente e em todos os outros comentários que se seguem acontece o mesmo: falam do principal partido opositor ao governo (até porque essa postagem data do dia 20 de outubro de 2014, quando só havia Aécio Neves e Dilma Rousseff na disputa) e falam da falta de legitimidade da fonte citada, mas não realizam uma contra argumentação ao conteúdo que fora lançado pelo oponente. O que não é necessariamente uma exclusividade desse grupo, já que essa estratégia pôde ser percebida nos comentários das páginas dos três candidatos em questão. O exemplo exposto evidencia que o embate não busca propriamente esclarecimento - não é, portanto, uma agonística para vencer um debate calcado em argumentos; mas sim um processo de "marcar território" (MAIA, 2017). Esse processo, por sua vez, parece ser apresentado com vistas a aliciar eleitores indecisos. Parece ser também reflexo do padrão adotado pelas campanhas políticas presidenciais: em que, muitas vezes, os candidatos se dedicaram mais ao ataque aos oponentes do que à exposição de propostas de governo.

\section{CONSIDERAÇÕES FINAIS}

Ao longo da análise dos dados coletados, foi possível perceber que os candidatos e seus grupos de eleitores empreendiam algumas estratégias semelhantes e outras divergentes daquelas desenvolvidas pelos concorrentes - formando dispositivos interacionais com nuances e lógicas próprias, conforme a estratégia adotada por cada grupo.

A página de Dilma se caracteriza como um dispositivo de tensionamentos, resultantes das interações estabelecidas pelos eleitores (pares e adversários) entre si. Quase não há, nessa página, a participação da equipe de campanha no espaço destinado aos comentários. A seleção das contribuições amadoras, que figurariam entre as produções profissionais no espaço das postagens, parecia ser o único momento em que era dada atenção às contribuições dos eleitores. Esses, por sua vez, esforçavam-se constantemente em apoiar os pares, ao mesmo tempo em que tentavam expulsar os eleitores oponentes - os quais tentavam, a cada nova postagem, desestabilizar e combater os argumentos do grupo dilmista. Aqui há ainda o constante manejo de microargumentos da ordem do sensível e do vivido, onde os testemunhos 
de vida se entrelaçam aos ambientes políticos para a defesa do legado petista. Em termos gerais, podemos caracterizar essa página como sendo um dispositivo de embates, de afetos e de escrita de si.

Já o dispositivo "página de Aécio no Facebook" funciona como uma espécie de central de atendimento, de espaço no qual os eleitores expõem suas queixas e medos em relação ao país e sua angústia diante da possibilidade de ver o PSDB, mais uma vez, perder a eleição presidencial para o Partido dos Trabalhadores. Ao que a equipe do candidato respondia sempre com mensagens de encorajamento, para os levar a crer que, com o apoio de todos, Aécio Neves venceria as eleições. A promessa era a de que a vitória do candidato significaria a salvação, diante da ameaça petista, e a resposta às demandas daquele grupo que o apoiava. Em postagens e comentários, o candidato tentava transparecer que compartilhava das mesmas revoltas e anseios do público que o acompanhava. O dispositivo opera, assim, como um espaço de simbiose entre a plataforma (sentimentos e propostas) do candidato e dos seus eleitores.

O dispositivo “página de Marina no Facebook”, por sua vez, é lugar onde são apontados direcionamentos específicos, por parte da equipe de campanha, de como os eleitores deveriam contribuir para que se alcançasse o objetivo final do grupo: a vitória na eleição presidencial. Mas, também, é lugar de discussão sobre o Programa de Governo e sobre o posicionamento que a candidata deveria adotar na campanha e nos debates televisivos. Esse nos parece o dispositivo que apresenta mais complexidades e diversidade - em termos de lógicas e estratégias de atuação e em termos de participação de eleitores com distintas posições perante a presidenciável (há os apoiadores fãs, há os crentes de que a candidata é enviada por Deus, há os apoiadores críticos, há os eleitores adversários e há ainda a tímida presença de indecisos). Esse é, portanto, um dispositivo instrucional (em que a equipe explica como os eleitores podem se tornar replicadores do conteúdo disponibilizado por eles); de embates (entre eleitores e até, numa dada situação, entre eleitor e equipe) e de afetos (entre pares e a equipe); e é ainda um dispositivo de esclarecimentos, de busca de consensos sobre a situação política e econômica do país e sobre as soluções apontadas pela candidata.

Para além das práticas automatizadas, os dispositivos estudados revelaram usos inventivos do meio técnico - como a iniciativa dos eleitores de Marina de prestar uma espécie de assessoria à campanha da candidata, dizendo-lhe como agir durante os debates; ou o compartilhamento de conteúdo produzido por amadores na página de Dilma; ou ainda a produção amadora de vídeos por parte do próprio candidato Aécio. 
O modelo interacional experimentado em 2014 assemelha-se às experimentações operacionalizadas em 2018: Jair Bolsonaro, candidato pelo PSL (Partido Social Liberal), abriu as portas da sua casa para que seus seguidores tivessem amplo acesso à sua rotina - através de registros fotográficos e audiovisuais, postados no Instagram oficial de Bolsonaro ou em páginas não-oficiais de apoiadores, que mostravam desde mesas de café da manhã aos descansos na sala de casa. Pode-se perceber, assim, que as estratégias que as campanhas políticas vêm desenvolvendo são possibilitadas, em alguns aspectos, pelas ferramentas das redes sociotécnicas, mas não determinadas por elas.

Nesse sentido, longe de querer aprofundar aqui o estudo das eleições de 2018, parecenos pertinente chamar a atenção para o encaminhamento e algumas reelaborações entre 2014 e a campanha recente. Um diferencial no emprego do Facebook em 2018 foram as constantes lives $^{8}$ realizadas pelo presidenciável vitorioso. Enquanto em 2014 o caráter amador e personalista das campanhas ficava por conta das contribuições de eleitores, imagens do candidato com a família, uso de linguagem coloquial, emoticons e vídeos filmados pela equipe em baixa resolução; em 2018, a equipe do candidato eleito faz sua própria experiência, enfatizando algumas dessas estratégias já acionadas pelas páginas aqui estudadas e elaborando outras. Enquanto que na campanha aqui analisada, as equipes deixavam claro que quem gerenciava aquele espaço era a assessoria do presidenciável e em cada página estava-se falando dele e não com ele; em 2018, Bolsonaro e outros políticos eleitos pelo PSL tentavam criar a sensação de contato direto com os eleitores, através de vídeos ao vivo no Facebook, de selfies, de fotos de suas rotinas (aparente postadas por eles mesmo) e de uma escrita em primeira pessoa em diversas redes sociais. Assim, todos os elementos que podiam ser postos a serviço do objetivo de ganhar - pessoalidade, efeito multiplicador, busca de adesão emocional, bater duro nos adversários, descarte da veracidade factual (o que importa é a versão), abandono de narrativas consistentes em favor do fragmento (discursivo e gestual), etc. - foram exploradas pelo presidenciável do PSL.

O fato de essas duas experiências, 2014 e 2018, apresentarem continuidades e diferenças substanciais indica, portanto, que as páginas dos candidatos no Facebook estão longe de caracterizar um dispositivo interacional político plenamente estabelecido. $\mathrm{O}$ que parece permanecer, desde a permissão do uso de sites de redes sociais em campanhas eleitorais pela legislação brasileira, em 2010, é: a tentativa de estabelecimento de zonas de

\footnotetext{
${ }^{8}$ Vídeos transmitidos ao vivo.
} 
contato entre candidatos (ou equipes de campanha) e eleitores; o uso dos espaços criados a partir da internet para o debate sobre os políticos e seus programas (ainda que o debate restrinja-se muitas vezes a um jogo de torcidas); e o incentivo para que os eleitores atuem como marqueteiros dos candidatos de sua predileção, ao mesmo tempo em que consomem as mensagens que lhe são endereçadas e fazem seguir adiante as narrativas que favorecem o grupo com o qual se identificam. Mas, o modo como esse processo vem sendo experimentado, dentro dos contextos político-social e técnico disponíveis (no momento de adoção de estratégias de campanha online), apresenta inovações a cada eleição. Os dispositivos "página do candidato" nos revelam, assim, processos de experimentação social que demandam cada vez mais investigação por parte dos pesquisadores da comunicação política.

\section{REFERÊNCIAS}

ALLCOTT, Hunt; GENTZKOW, Matthew. Social Media and Fake News in the 2016 Election, NBER Working Paper. No. 23089, 2017.

ALMEIDA, Jorge. Cultura política e marketing na campanha de Dilma Rousseff em 2014. In: Anais do VI Congresso da Associação Brasileira de Pesquisadores em Comunicação e Política

(COMPOLÍTICA). Rio de Janeiro (PUC-Rio), 2015.

BARIFOUSE, 2014. Eleições 2014: Novos Hábitos Criam Pleito Mais Conectado do Mundo. BBC, 29 out. 2014. Disponível em:

<http://www.bbc.co.uk/portuguese/noticias/2014/10/141028_eleicoes2014_internet_rb>, Acesso em: 07 nov. 2014.

BRAGA, José Luiz. Dispositivos Interacionais. In Anais do XX Encontro Anual da Compós, GT Epistemologias da Comunicação, Porto Alegre: UFRGS, 14 a 17 de junho. Disponível em: http://www.compos.org.br/data/biblioteca_1657.doc ,2011. Acesso em: 05 nov. 2014.

. Dispositivos Interacionais. In: BRAGA, José Luiz \& CALAZANS, Regina (org.) Matrizes Interacionais - a comunicação constrói a sociedade. 1. ed. Campina Grande: EDUEPB - Editora da Universidade Estadual da Paraíba, 2017.

CAPELAS, Bruno. Eleição de 2014 é a maior da história do Facebook no mundo. Estadão, 05 out. 2014. Disponível em: < https://link.estadao.com.br/noticias/geral,eleicao-de-2014-e-a-maior-dahistoria-do-facebook-no-mundo,10000030373>. Acesso em: 20 nov. 2014.

HARLOW, Summer. It was a Facebook Revolution: Exploring the Media Narratives of the Egyptian Protests. Revista de Comunicacion, 59-82, 59-82. 2013.

MAIA, Lídia R. H. A política dos eleitores no Facebook dos candidatos: processos interacionais online nas eleições presidenciais de 2014. In: Anais do XXVI Encontro Anual da Compós, São Paulo: Universidade Cásper Líbero, 06 a 09 de junho. Disponível em: 
<http://www.compos.org.br/data/arquivos_2017/trabalhos_arquivo_4FIHT58BO5D405KQ810T_26_5 651_18_02_2017_18_52_47.pdf>. 2017.

. A política dos eleitores no Facebook dos candidatos: uma análise de dispositivos interacionais construídos nas eleições presidenciais de 2014. Tese (Doutorado) - Universidade do Vale do Rio dos Sinos, Programa de Pós-Graduação em Ciências da Comunicação, São Leopoldo, 2019.

PÁGINA Oficial de Aécio Neves. Disponível em: < https://www.facebook.com/AecioNevesOficial/?fref=ts>. Acesso em: 10 fev. 2015.

PÁGINA Oficial de Dilma Rousseff. Disponível em: < https://www.facebook.com/DilmaRousseff/?fref=ts>. Acesso em: 20 nov. 2014.

PÁGINA Oficial de Marina Silva. Disponível em: <

https://www.facebook.com/marinasilva.oficial/?fref=ts>. Acesso em: 12 mar. 2015.

PARISER, Eli. The Filter Bubble: What the Internet Is Hiding From You. Penguin Press, 2011.

PENTEADO, Claudio Luis et al. O PLANALTO EM DISPUTA NO FACEBOOK: Um estudo dos perfis de Dilma Rousseff e Aécio Neves nas eleições de 2014. In: Cervi, Emerson U; Massuchin, Michele G; Carvalho, Fernanda C de (org.). Internet e Eleições no Brasil. Curitiba: CPOP (grupo de pesquisa em Comunicação Política e Opinião Pública), 2016. 430 p. 1ed. E-book.

ROSSINI, Patrícia et al. O uso do Facebook nas eleições presidenciais brasileiras de 2014: A influência das pesquisas eleitorais nas campanhas online. In: Cervi, Emerson U; Massuchin, Michele G; Carvalho, Fernanda C de (org.). Internet e Eleições no Brasil. Curitiba: CPOP (grupo de pesquisa em Comunicação Política e Opinião Pública), 2016. 430 p. 1ed. E-book.

RUEDIGER, Marco A. Robôs, redes sociais e política no Brasil: estudo sobre interferências ilegítimas no debate público na web, riscos à democracia e processo eleitoral de 2018 / Edited by Marco Aurélio Ruediger - Rio de Janeiro: FGV, DAPP. 2017.

SANTOS JÚNIOR, Marcelo. AGENTES DE CAMPANHA NÃO-OFICIAL: A Rede Antipetista na eleição de 2014. In: Anais do XXV Encontro Anual da Compós, Goiânia (Universidade Federal de Goiás). 2016.

SCHOPENHAUER, Arthur. 38 estratégias para vencer qualquer debate: a arte de ter razão. São Paulo: Faro Editorial, 2014.

SORENSEN, Mads. Political conversations on Facebook - the participation of politicians and citizens. Media, Culture \& Society, Vol. 38(5), 664 -685. 2016.

WATSON, Rod; GASTALDO, Édison. Etnometodologia \& Análise da Conversa. Rio de Janeiro: Editora Vozes; Rio de Janeiro: Editora PUC-Rio, 2015.

UOL, 2014. Pesquisas eleitorais. Disponível em <: https://eleicoes.uol.com.br/2014/pesquisaseleitorais/brasil/2-turno/>. Acesso em: 20 nov. 2014. 


\section{Lídia Raquel Herculano Maia}

Professora substituta na Graduação em Relações Públicas da Universidade Federal da Paraíba. Doutora em Comunicação pela Universidade do Vale do Rio dos Sinos, com estágio doutoral na Florida State University (Bolsa Capes/PDSE). Mestre em Estudos da Mídia pela Universidade Federal do Rio Grande do Norte. Graduada em Comunicação Social, com habilitação em Publicidade e Propaganda, pelo Instituto de Educação Superior da Paraíba. Membro dos grupos de pesquisa CACTO

- Comunicação, Afeto, Cultura, Trabalho e Organizações - (UFPB) e Infotenimento e Redes

(Unipampa/RS).

\section{(9) $(\Theta \Theta \odot$}

Esta obra está licenciada com uma Licença

Creative Commons Atribuição-NãoComercial-CompartilhaIgual 4.0 Internacional 